\title{
Successful bone marrow transplantation in a patient with Diamond-Blackfan anemia with co-existing Duchenne muscular dystrophy: a case report
}

\author{
Velu Nair ${ }^{1 *}$, Satyaranjan Das ${ }^{1}$, Ajay Sharma ${ }^{1}$, Sanjeevan Sharma ${ }^{1}$, Jasmeet Kaur ${ }^{2}$ and DK Mishra ${ }^{3}$
}

\begin{abstract}
Introduction: Diamond-Blackfan anemia and Duchenne muscular dystrophy are two rare congenital anomalies. Both anomalies occurring in the same child is extremely rare. Allogeneic hematopoietic stem cell transplantation is a well-established therapy for Diamond-Blackfan anemia. However, in patients with Duchenne muscular dystrophy, stem cell therapy still remains experimental.

Case presentation: We report the case of a nine-year-old boy of north Indian descent with Diamond-Blackfan anemia and Duchenne muscular dystrophy who underwent successful allogeneic hematopoietic stem cell transplantation. He is transfusion-independent, and his Duchenne muscular dystrophy has shown no clinical deterioration over the past 45 months. His creatine phosphokinase levels have significantly decreased to $300 \mathrm{U} / \mathrm{L}$ from 14,000 U/L pre-transplant. The patient is $100 \%$ donor chimera in the hematopoietic system, and his muscle tissue has shown $8 \%$ to $10.4 \%$ cells of donor origin.

Conclusion: Our patient's Diamond-Blackfan anemia was cured by allogeneic hematopoietic stem cell transplantation. The interesting clinical observation of a possible benefit in Duchenne muscular dystrophy cannot be ruled out. However, further clinical follow-up with serial muscle biopsies and molecular studies are needed to establish this finding.
\end{abstract}

\section{Introduction}

Diamond-Blackfan anemia (DBA) is a rare congenital hypoplastic anemia that usually presents in infancy and childhood. The incidence of DBA is five to 10 per one million births, and more than 600 cases have been reported worldwide. The exact cause is unclear, but the problem is a defect in one of the early steps in erythropoiesis (red blood cell (RBC)) production. In about 15\% of affected children, there is a defect within a gene called RPS19 (ribosomal protein S19) [1]. In most cases, occurrence is sporadic, but in subsequent generations, inheritance is usually autosomal dominant. Nearly $90 \%$ of these children are transfusion-dependent by 18 months of age. About $60 \%$ of patients initially respond to drugs such as steroids,

\footnotetext{
* Correspondence: nairvelu2000@yahoo.com

'Department of Haematology \& Bone Marrow Transplantation, Army Hospital (Research \& Referral), Delhi Cantt-110010, India

Full list of author information is available at the end of the article
}

androgens and cyclosporine, though one-half of these initial responders become refractory to these medications later [2]. The only curative treatment for DBA is allogeneic hematopoietic stem cell transplant (allo-HSCT), which has an $85 \%$ success rate [3-5] and is offered to patients who do not respond to or become refractory to drug therapy.

Duchenne muscular dystrophy (DMD), which is caused by mutation of the dystrophin gene, is the most common and severe form of muscular dystrophy. This disorder is marked by progressive loss of muscle function which begins in the lower limbs and later occurs in the arms, neck and other areas. DMD occurs in approximately one of 3500 male live births and is inherited in an X-linked recessive pattern [6]. Terminally, the respiratory muscles are also involved. The calf muscles initially grow larger (pseudo-hypertrophy) but are eventually replaced by fat and connective tissue. The muscle fibers shorten because of fibrosis. The diagnosis is suspected when the creatine

\section{C) Biomed Central}

(C) 2011 Nair et al; licensee BioMed Central Ltd. This is an Open Access article distributed under the terms of the Creative Commons Attribution License (http://creativecommons.org/licenses/by/2.0), which permits unrestricted use, distribution, and reproduction in any medium, provided the original work is properly cited. 
phosphokinase (CPK) levels are highly elevated and is confirmed by muscle biopsy. There is no known cure for DMD, and treatment is only supportive. However, recently there have been anecdotal reports of benefit following allo-HSCT treatment [7-10].

\section{Case presentation}

DBA and DMD are two rare congenital anomalies. Both anomalies occurring in the same child is extremely rare. We report such an unusual case of a nine-year-old boy of north Indian descent, the third of four siblings born to healthy, non-consanguineous parents with a family history of DMD in a maternal first cousin. The boy was presented to our hospital at the age of eight months with progressive pallor and failure to thrive. He was diagnosed with DBA on the basis of peripheral blood showing normocytic, macrocytic anemia and reticulocytopenia with normocellular bone marrow showing erythroblastopenia. Though initially steroid-responsive, the boy later became unresponsive to both steroids and cyclosporine. By the fourth year of life, he was completely transfusion-dependent, and iron chelation was started only in the sixth year of life with intravenous desferrioxamine when his serum ferritin level was found to be $5100 \mathrm{ng} / \mathrm{mL}$.

The patient had normal milestones until the fourth year of life. Thereafter he developed lower-limb weakness and calf muscle pseudohypertrophy. The weakness was progressive in nature, and by the age of five years the boy required support to climb stairs. His CPK level was high (5939 U/L), and his electromyogram was consistent with myopathy. He was diagnosed with DMD. A muscle biopsy was not done as the parents were unwilling to allow their son to undergo the procedure at that time. At this stage, the child was referred to our center for alloHSCT treatment in view of his transfusion-dependent DBA with hyperferritinemia. The diagnosis was reconfirmed at our center. He also had dysmorphic facial features. However, RPS19 genetic studies could not be done.

The child had an unaffected elder brother who was a human leukocyte antigen (HLA)-identical match (6/6 antigen match) and underwent myeloablative allo-HSCT treatment. The conditioning regimen comprised busulphan (16 mg/kg over four days), cyclophosphamide (200 $\mathrm{mg} / \mathrm{kg}$ over four days) and equine anti-thymocyte globulin (Atgam; Pfizer(Pharmacia \& Upjohn company, a subsidiary of Pharmacia Corporation

Kalamazoo, Michigan 49001, USA) (90 mg/kg over three days). There was a minor blood group mismatch, with the recipient being in the $\mathrm{B}+\mathrm{ve}$ group and the donor being in the $\mathrm{O}+\mathrm{ve}$ blood group. Granulocyte colony-stimulating factor primed bone marrow was harvested from the donor while the donor was under general anesthesia. Plasma depletion was done using a Cryofuge 6000i centrifuge(by Heraeus Instruments made in Germany and supplied by
Kendro Labarotories (India)) at $3000 \mathrm{rpm}$, and plasmadepleted marrow was infused with a cell dose of $6 \times 10^{8}$ mononuclear cells (MNCs)/kg body weight. Graft-versushost disease (GVHD) prophylaxis consisted of standard dose methotrexate and cyclosporine. Neutrophil and platelet engraftment occurred on day+11 and day+16, respectively. RBC engraftment was confirmed with a change of blood group on day+90. The child has been transfusionfree since 2 months post-transplant, and his serum ferritin levels have been reduced to $600 \mathrm{ng} / \mathrm{mL}$ with regular phlebotomies. The boy's blood counts were normal 45 months after allo-HSCT treatment: hemoglobin $13.5 \mathrm{~g} / \mathrm{dL}$, reticulocyte count $1 \%$, white blood cell count $6.0 \times 10^{3} / \mu \mathrm{L}$ with $70 \%$ neutrophils and platelet count $1900 \times 10^{3} / \mu \mathrm{L}$.

This patient was evaluated by a neurologist pretransplant and periodically post-transplant. The patient was wheelchair-bound pre-transplant, and, 45 months post-transplant, there has been no clinical deterioration whatsoever in the boy's motor power. He continues to be wheelchair-bound and is able to sit on his own for more than three hours at a stretch. The CPK level pre-transplant had been in the range of 9000 to $14,000 \mathrm{U} / \mathrm{L}$ and showed a declining trend within four weeks of transplantation, reaching a nadir of $300 \mathrm{U} / \mathrm{L}$ by six months post-transplantation. The muscle biopsy, which was done twice at 730 and 1250 days postHSCT, respectively, revealed mixed donor chimerism with $8 \%$ to $10 \%$ cells of donor origin. Sequential chimerism studies using whole blood established trilineage engraftment with $100 \%$ donor chimerism. There were no post-transplant complications in the form of sepsis, hepatic veno-occlusive disease or acute or chronic GVHD.

Chimerism analysis performed on recipient peripheral blood samples on day +30 , day +90 , day +365 , day +730 and day +1250 revealed complete donor chimerism posttransplant. A muscle biopsy was performed twice postbone marrow transplantation (BMT) at days 730 and 1250 to study histopathology, dystrophin expression and chimerism status. Immunostaining for dystrophin I was reduced, dystrophin II and III were absent and there was up-regulation of utrophin.

Chimerism was performed to monitor donor cell engraftment in the recipient peripheral blood and was also used to detect donor cells in the muscle biopsy from the recipient. Chimerism was carried out using recipient's hair follicle as the pre-transplant sample [11], peripheral whole blood as the post-HSCT sample, and whole blood sample from the donor. Blood was collected in ethylenediaminetetraacetic acid vacutainers. DNA extraction from whole blood was carried out using the QIAamp DNA Blood Mini Kit (Qiagen, Hilden, Germany) according to the manufacturer's instructions. Preparation of hair follicles was done with 10 full-length hairs with 
roots plucked from different areas of the recipient's scalp. The presence of the hair bulb was visually confirmed. Careful washing was done to minimize the risk of blood contamination by rinsing in normal saline. The QIAamp DNA Mini Kit was used for DNA extraction from hair roots and muscle biopsy. The muscle biopsy specimen was preserved in $10.4 \%$ formaldehyde for routine histopathological processing and stained with hematoxylin and eosin (Figure 1).

The fragment of muscle biopsy taken for chimerism analysis was washed in saline seven times to remove all traces of RBCs and peripheral blood MNCs (PBMCs). The muscle tissue was homogenized and further rinsed three times in saline, following which a frozen section of the homogenized muscle was taken to check for any contamination with PBMCs (Figure 2). Genomic DNA was extracted from the muscle tissue cryosections serially cut from biopsies using the QIAamp DNA Blood Mini Kit according to the manufacturer's instructions.

Chimerism of all samples was performed using 16 short tandem repeat markers (D8S1179, D21S11, D7S820, CSF1PO, D3S1358, THO1, D13S317, D16S539, D2S1338, D19S433, vWA, TPOX, D18S51, AMEL, D5S818 and FGA) labeled with four types of fluorescent dyes (6FAM, VIC, NED and PET). A multiplex polymerase chain reaction assay was performed in a final reaction volume of $25 \mu \mathrm{L}$ containing $10.5 \mu \mathrm{L}$ of reaction mixture, $5.5 \mu \mathrm{L}$ of primer mix, $0.5 \mu \mathrm{L}$ of AmpFl STR Identifier kit (Applied Biosystems, Foster City, CA, USA) and $10 \mu \mathrm{L}$ of DNA at a concentration of $0.2 \mathrm{ng} /$ $\mu \mathrm{L}$. Cycling parameters were optimized as follows: $95^{\circ} \mathrm{C}$ for 11 minutes (one hold), $94^{\circ} \mathrm{C}$ for 60 seconds, $59^{\circ} \mathrm{C}$ for 60 seconds, $72^{\circ} \mathrm{C}$ for 60 seconds and 28 cycles, $60^{\circ} \mathrm{C}$ for

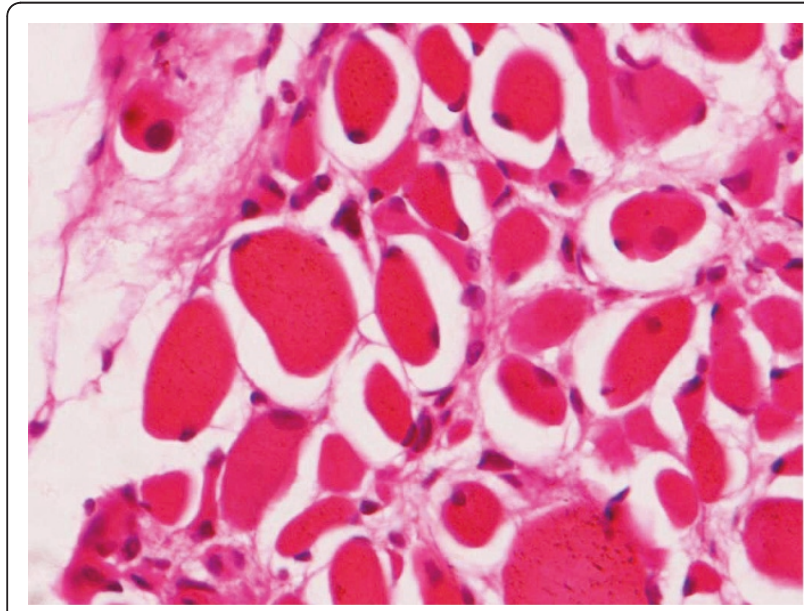

Figure 1 Hematoxylin and eosin-stained section showing posttransplantation muscle biopsy. Image shows a cross-sectional view of muscle fibers of varying sizes that have predominantly peripheral nuclei with a few fibers displaying central nuclei and regenerative changes. There is scanty intervening stroma.

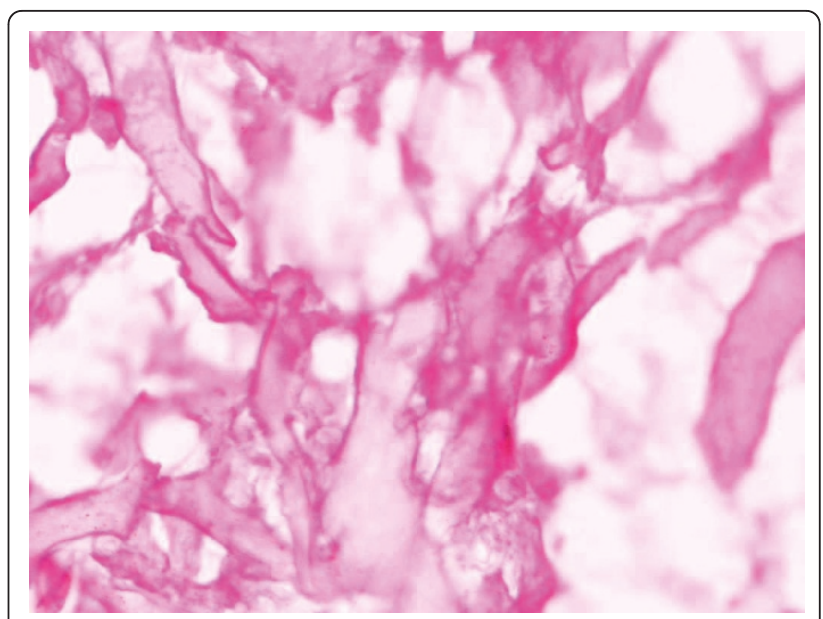

Figure 2 Hematoxylin and eosin-stained cryosections of serially cut biopsies of muscle tissue that was homogenized and washed with saline prior to extraction of tissue DNA. No evidence of mononuclear cell contamination of the muscle fibers was noted.

60 minutes (two holds) in a GeneAmp PCR System 9700 (Applied Biosystems). Denaturation was performed for five minutes at $95^{\circ} \mathrm{C}$ using $\mathrm{Hi}$-Di Formamide and GeneScan 500 LIZ Size Standard (both from Applied Biosystems). The amplicon was resolved by performing capillary electrophoresis using the ABI Prism 3100Avant Genetic Analyzer System (Applied Biosystems) and analyzed using the Applied Biosystems Gene mapper TM software v 3.5, Foster City CA 94404, USA. To determine the fraction of donor cells in the recipient's peripheral blood and muscle biopsy samples post-transplantation, the informative markers were identified and the percentage of donor cells was estimated. While the post-transplant recipient peripheral blood sample displayed complete donor chimerism, the muscle biopsy sample showed mixed donor chimerism with $8 \%$ to $10.4 \%$ donor cells on days 730 and 1250, respectively (Figure 3), suggesting the presence of donor-derived cells in the recipient's muscle.

\section{Discussion}

Allo-HSCT is the only available curative treatment for DBA. The first "successful" allo-HSCT treatment of DBA was reported in 1976 [12]. The patient died, but hematopoietic engraftment from donor bone marrow confirmed DBA as a transplantable disease. Since the initial case, more than 70 transplants, the majority of which involved from HLA-matched sibling donors, have been reported in the literature [13,14]. The outcomes of patients who undergo alternative donor stem cell transplantation are significantly inferior to those of HLAmatched sibling donors [14]. 


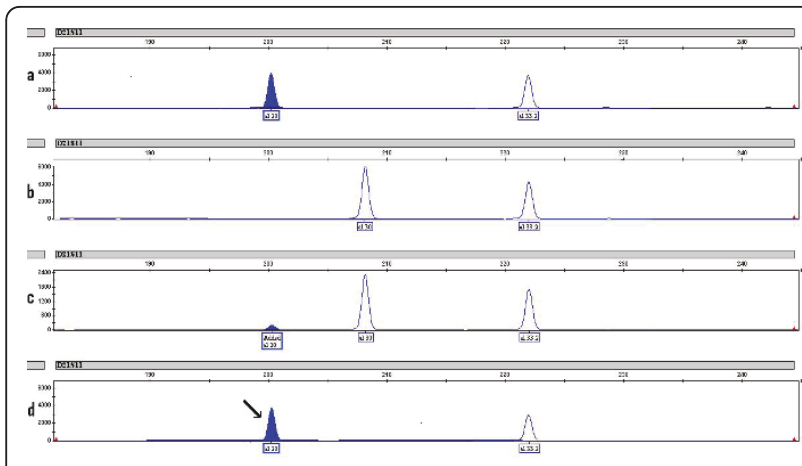

Figure 3 Microsatellite analysis of locus D21S11 in (a) donor peripheral blood sample showing peaks at allele 28 and 33.2, (b) recipient hair follicle representing patient pre-transplant DNA with allele 30 and 33.2, (c) recipient muscle biopsy sample on D+730 showing mixed chimerism with alleles 28,30 and 33.2 and (d) recipient peripheral blood sample on $D+730$ showing complete donor chimerism.

DMD has no known cure. Experiments with stem cells on animals with DMD have been encouraging. In $m d x$ mouse models of DMD, allo-HSCT from normal mice led to incorporation of donor-derived nuclei into muscle and partial restoration of dystrophin expression in the affected muscle. The canine model of DMD (canine Xlinked muscular dystrophy (CXMD)) has shown a clinical course very similar to that of human DMD. In a study of seven CXMD dogs that underwent allo-HSCT from non-affected littermates, there was no increase in the number of dystrophin-positive fibers or in the amount of wild-type dystrophin RNA post-transplantation compared with pre-transplantation levels. However, another canine study demonstrated that allo-HSCT provides an immune-tolerant platform for myoblast transplantation from freshly isolated muscle-derived cells from the same HSCT donor [15].

The first successful allo-HSCT in a patient with DMD was reported in 2002. That patient with DMD was diagnosed at 12 years of age and underwent BMT at one year of age for X-linked severe combined immunodeficiency syndrome. Analysis of muscle biopsies revealed the presence of donor nuclei within a small number of muscle myofibers $(0.5 \%$ to $0.9 \%)$. The discovery of the donor's mesenchymal cells in the patient's muscle tissue and bone marrow 13 years after the transplant raised the hope that BMT may play a role in the treatment of DMD [7]. Two case reports from China of unrelated allogeneic umbilical cord HSCT in young boys with advanced DMD have shown some improvement posttransplantation. This improvement has been reported both clinically by improved motor activity and in laboratory parameters seen by reduction in CPK levels, increase in dystrophin-positive muscle fibers and reduction of the defective gene transcripts measured by PCR $[9,10]$.

\section{Conclusion}

To the best of our knowledge, we report the first case of a boy with two rare genetic disorders, DBA and DMD, who successfully underwent myeloablative allo-HSCT, which cured his DBA and might have had a positive effect on his DMD. Clinically, the course of his DMD has seemed milder and nearly static over the past 45 months as compared to his first cousin, who also has DMD and by the same age was unable to sit without support. In addition, CPK levels showed drastic reduction, and chimerism studies revealed $8 \%$ and $10.4 \%$ donor cells in the patient's skeletal muscle at days 730 and 1250 , respectively.

Though this percentage of donor cells was small, the presence of these cells in the patient's muscle tissue indicates the possibility of transdifferentiation of hematopoietic donor stem cells to skeletal muscle myocytes in the patient. However, no dystrophin expression was noted in the muscle tissue, which could possibly be due to the low level of transdifferentiation. Though this transplant was done primarily for DBA, it raises the interesting possibility of allo-HSCT's being beneficial in the treatment of DMD, which is an otherwise incurable disease with $100 \%$ mortality. However, further clinical follow-up with serial muscle biopsies and molecular studies is needed to document the extent and duration of mixed chimerism in skeletal muscle in this patient. The purpose of this case report is to describe this interesting observation of a possible benefit in DMD and not to suggest HSCT as a modality of treatment until further studies show an unequivocal benefit, given the inherent risks associated with HSCT.

\section{Consent}

Written informed consent was obtained from the patient's parent for publication of this case report and accompanying images. A copy of the written consent is available for review by the Editor-in-Chief of this journal.

\section{Author details}

${ }^{1}$ Department of Haematology \& Bone Marrow Transplantation, Army Hospital (Research \& Referral), Delhi Cantt-110010, India. ${ }^{2}$ Department of Microbiology, Army Hospital (Research \& Referral), Delhi Cantt-110010, India ${ }^{3}$ Department of Pathology, Army Hospital (Research \& Referral), Delhi Cantt110010, India.

\section{Authors' contributions}

BVN is the first author and is responsible for the conception and design of the case report. Contributing authors SD, AS, SS, JK and DKM made substantial contributions to the design of the manuscript and the acquisition, analysis and interpretation of the data. 


\section{Authors' information}

VN is a consultant in Medicine \& Clinical Haematology and was Head of the Department of Medicine and Head of the Department of Haematology \& BMT, Army Research \& Referral Hospital, New Delhi, India, which is the premier institution of the Indian Armed Forces. He was also the Dean of the Army College of Medical Sciences, New Delhi, India. Presently, he is Head of the Department of Medicine at the Armed Forces Medical College in Pune, India. He is a well-known clinician, researcher and BMT physician with over 25 years of experience. He has written more than 150 publications in various national and international journals, including Bone Marrow Transplantation, Acta Haematologica, Blood, Journal of the Association of Physicians of India, Indian Pediatrics. Medical Journal of Armed Forces of India and Indian Journal of Haematology \& Blood Transfusion among others. VN has done two International Cancer Technology Transfer Fellowships under the technology transfer program of the International Union Against Cancer, Geneva, at King's College \& Hospital, London in 2004, and at Stanford University School of Medicine, Stanford, CA, USA, in 2008. He is also the former President of the Indian Society of Haematology \& Transfusion Medicine and a fellow of the American College of Physicians and the Indian Academy of Medical Sciences.

All other contributing authors are either professors or associate professors in the specialties mentioned on the title page and have significant experience and have written numerous publications.

\section{Competing interests}

The authors declare that they have no competing interests.

Received: 30 June 2010 Accepted: 4 June 2011 Published: 4 June 2011

\section{References}

1. Orfali KA, Ohene-Abuakwa Y, Ball SE: Diamond Blackfan anemia in the UK: clinical and genetic heterogeneity. Br J Haematol 2004, 125:243-252.

2. Alter BP: Inherited bone marrow failure syndromes. In Nathan and Oski's Hematology of Infancy and Childhood. Volume 1.. 6 edition. Edited by: Nathan DG, Orkin SH, Ginsburg D, Look AT, Oski FA. Philadelphia: PA Saunders; 2003:280-365, \{AU: This is a two-volume set; please indicate which volume this chapter is in.\}.

3. Iriondo A, Garijo J, Baro J, Conde E, Pastor JM, Sabanés A, Hermosa V, Sainz MC, Pérez de la Lastra L, Zubizarreta A: Complete recovery of hemopoiesis following bone marrow transplant in a patient with unresponsive congenital hypoplastic anemia (Blackfan-Diamond syndrome). Blood 1984, 64:348-351.

4. Ohga S, Mugishima H, Ohara A, Kojima S, Fujisawa K, Yagi K, Higashigawa M, Tsukimoto I, Aplastic Anemia Committee Japanese Society of Pediatric Hematology: Diamond-Blackfan anemia in Japan: clinical outcomes of prednisolone therapy and hematopoietic stem cell transplantation. Int I Hematol 2004, 79:22-30.

5. Nair V, Das S, Sharma A: Hematopoietic stem cell transplantation in children with genetic defects. Indian Pediatr 2009, 46:241-243.

6. Den Dunnen JT, Grootscholten PM, Bakker E, Blonden LA, Ginjaar HB, Wapenaar MC, van Paassen HM, van Broeckhoven C, Pearson PL, van Ommen GJ: Topography of the Duchenne muscular dystrophy (DMD) gene: FIGE and CDNA analysis of 194 cases reveals 115 deletions and 13 duplications. Am J Hum Genet 1989, 45:835-847.

7. Gussoni E, Bennett RR, Muskiewicz KR, Meyerrose T, Nolta JA, Gilgoff I, Stein J, Chan YM, Lidov HG, Bönnemann CG, Von Moers, Morris GE, Den Dunnen JT, Chamberlain JS, Kunkel LM, Weinberg K: Long-term persistence of donor nuclei in a Duchenne muscular dystrophy patient receiving bone marrow transplantation. J Clin Invest 2002, 110:807-814.

8. Cooke R: Stem cells aimed at muscular dystrophy: evidence suggests a future treatment. Newsday 2002.

9. Zhang C, Feng HY, Huang SL, Fang SW, Xu HG, Huang K, Zhou DH, Chen W, Xie YM, Xi J Zhang M, Li Y, Liu Y: [Therapy of Duchenne muscular dystrophy with umbilical cord blood stem cell transplantation] [in Chinese]. Zhonghua Yi Xue Yi Chuan Xue Za Zhi 2005, 22:399-405.

10. Zhang C, Chen W, Xiao LL, Tan EX, Luo SK, Zheng D, Ye X, Li Z, Lu XL, Liu Y: [Allogeneic umbilical cord blood stem cell transplantation in Duchenne muscular dystrophy] [in Chinese]. Zhonghua Yi Xue Za Zhi 2005, 85:522-525.

11. Hong YC, Liu HM, Chen PS, Chen YJ, Lyou JY, Hu HY, Yi MF, Lin JS, Tzeng CH: Hair follicle: a reliable source of recipient origin after allogeneic stem cell transplantation. Bone Marrow Transplant 2007, 40:871-874.

12. August CS, King E, Githens JH, McIntosh K, Humbert JR, Greensheer A, Johnson RB: Establishment of erythropoiesis following bone marrow transplantation in a patient with congenital hypoplastic anemia (Diamond-Blackfan syndrome). Blood 1976, 48:491-498.

13. Vlachos A, Alter B, Buchanan G, et al: The Diamond Blackfan Anemia Registry (DBAR): preliminary data [Abstract 339]. Blood 1993, 82(Suppl 1):88.

14. Vlachos A, Federman N, Reyes-Haley C, Abramson J, Lipton JM: Hematopoietic stem cell transplantation for Diamond Blackfan anemia: a report from the Diamond Blackfan Anemia Registry. Bone Marrow Transplant 2001, 27:381-386.

15. Parker MH, Kuhr C, Tapscott SJ, Storb R: Hematopoietic cell transplantation provides an immune-tolerant platform for myoblast transplantation in dystrophic dogs. Mol Ther 2008, 16:1340-1346.

doi:10.1186/1752-1947-5-216

Cite this article as: Nair et al: Successful bone marrow transplantation in a patient with Diamond-Blackfan anemia with co-existing Duchenne muscular dystrophy: a case report. Journal of Medical Case Reports 2011 5:216.

\section{Submit your next manuscript to BioMed Central and take full advantage of:}

- Convenient online submission

- Thorough peer review

- No space constraints or color figure charges

- Immediate publication on acceptance

- Inclusion in PubMed, CAS, Scopus and Google Scholar

- Research which is freely available for redistribution

Submit your manuscript at www.biomedcentral.com/submit
Ciomed Central 